\title{
DNA amplification fingerprinting in coconut: protocol optimization and analysis of resistance to root (wilt) disease
}

\author{
K. Jayadev ${ }^{\mathrm{a}}$, M.K. Rajesh ${ }^{\mathrm{a},{ }^{*}, \text { K. Devakumar }}{ }^{\mathrm{a}}$, Regi Jacob Thomas ${ }^{\mathrm{b}}$, R.V. Nair ${ }^{\mathrm{b}}$ and \\ V.A. Parthasarathy ${ }^{\mathrm{c}}$
}

\begin{abstract}
Root (wilt) disease is a serious malady in coconut causing a loss of approximately 968 million nuts a year in India. Integrated management practices are the only suggested methods to reduce its effect to some extent, while the development of resistant varieties will offer a permanent solution for which concrete breeding efforts are required. Considering the long life cycle of coconut, selection of resistant varieties through conventional methods will be time consuming and laborious. Molecular markers offer numerous advantages over markers traditionally used in plant mapping and selective breeding. Here, we present the optimization of PCR conditions for DNA amplification fingerprinting (DAF) of coconut using arbitrary oligonucleotide primers. Three of the primers could detect variations between root (wilt) resistant and susceptible coconut palms. This study constitutes the basis for future efforts to tag the root (wilt) resistant gene(s) in coconut.
\end{abstract}

Key words: Root (wilt) disease, DNA amplification fingerprinting, oligonucleotide primers, coconut, host plant resistance.

\footnotetext{
${ }^{a}$ Central Plantation Crops Research Institute, Kasaragod 671124, Kerala, India.

${ }^{\mathrm{b}}$ CPCRI (RS), Kayamkulam 690533, Kerala, India.

${ }^{\mathrm{c}}$ Indian Institute of Spices Research, Kozhikode 673012, Kerala, India.

("Corresponding author. Tel.: +91-4994-232894; fax: +91-4994-232322;

e-mail:mkraju_cpcri@yahoo.com)
} 


\section{Introduction}

Root (wilt) disease is one of the most serious maladies affecting the coconut palm in India. This disease was reported for the first time from Erattupetta area of Meenachil Taluk in Kottayam district of Kerala State of India in 1884 (Butler, 1908; Pillai, 1911). It has since then spread from the original foci of infection and currently occupies a contiguous area covering eight districts of Kerala and the adjoining areas of Tamil Nadu State. The diagnostic symptoms of the disease are the characteristic bending of the leaflets termed as 'flaccidity', yellowing and necrosis (Radha and Lal, 1972). The disease is debilitating in nature, but not lethal, and gradually reduces the yield of nuts, ultimately rendering the palms nearly barren. The annual loss due to this disease is estimated to be 968 million nuts (Anonymous, 1985). Leaf rot occurs superimposed over $>60 \%$ of the root (wilt) affected palms (Sreenivasan, 1991). Integrated management practice has been recommended to increase the productivity of palms in severely affected areas (Muralidharan et al., 1986; Mathewkutty, 1998). As the disease cannot be controlled by conventional methods, development of resistant varieties is the only practical solution.

To develop resistant varieties, it is necessary to (i) screen available germplasm for disease resistance / tolerance, along with other important yield contributing traits and identify gene(s) responsible, (ii) introgress these gene(s) into high yielding varieties to get disease resistant/ tolerant high yielding varieties and hybrids and (iii) large-scale propagation of these resistant /tolerant high yielding palms.

Earlier studies have shown that none of the so far tested coconut accessions and hybrids are completely resistant / tolerant to root (wilt) disease (Jacob et al., 1998). As an initial step towards breeding for resistance / tolerance to root (wilt) disease, an intensive survey covering the heavily root (wilt) affected areas ('hot spots') of Kottayam, Alappuzha, Pathanamthitta and Kollam districts of Kerala State was initiated during 1985 (Anonymous, 1986). Some diseasefree, high yielding cultivars such as West Coast Tall and Chowghat Green Dwarf were identified by plant breeders in these areas and these palms are being used in breeding programmes since 1988 (Nair et al., 1996).

Considering the long life cycle of coconut palms and their low multiplication rate, the task of examining myriad individual palms to identify the presence or absence of morphological markers for resistance is an arduous and timeconsuming job. Molecular markers (RFLP, RAPD, AFLP, SSR and DAF) offer numerous advantages over morphological markers traditionally used in plant mapping, as they are much faster, more highly discriminating and less costly. They have become powerful tools for marker-assisted selection of resistant genotypes in many crop species.

DNA amplification fingerprinting (DAF) employs single arbitrary primers as short as 5 nucleotides in length to produce characteristic and highly informative DNA patterns (CaetanoAnollès et al., 1992). These patterns are adequately resolved by polyacrylamide gel electrophoresis and silver stained. DAF can be distinguished from other genome scanning techniques by high primers to template ratio, simplicity, and excellent reproducibility. DAF has been used for identity testing phylogenetic relationships, population and pedigree analysis, molecular characterization, high density mapping, tagging useful genes and marker assisted selection (He et al., 1995; Yazdi-Samadi et al., 1996; Caetano-Anollès et al., 1995; Shahnejat et al., 1999; Richard-Molard et al., 1999; Assefa et al., 1999).

A typical DAF reaction involves the use of a single primer usually composed of 8 to 12 nucleotides, a length that approaches the minimum configuration for DNA amplification (Caetano-Anollès et al., 1992; Vincent et al., 1994). Amplification conditions discriminate bonafide amplicons from those of artifactual origin, and a non-stringent reaction environment ensures the reproducible targeting of multiple 
sites (Caetano-Anollès et al., 1991). To guarantee optimal performance and reproducibility, a good understanding of primer design and a careful optimization exercise of amplification parameters are required. The specificity, efficiency and fidelity of DNA amplification are strongly influenced by the different components of the reaction (such as primer, magnesium and deoxynucleotide triphosphate concentrations) and are modulated by thermocycling conditions (such as annealing temperature). These conditions need to be optimized to avoid non-specific amplification products such as primer-dimers. Similarly conditions to detect DNA on gel need to be optimized to improve the efficiency of DAF analysis.

The present study was undertaken to optimize PCR conditions for DAF analysis in coconut and screening of primers for detecting variations between root (wilt) field resistant and susceptible coconut palms.

\section{Materials and methods}

\section{Plant materials}

The leaf samples were collected from 37 root (wilt) field resistant and 43 susceptible West Coast Tall palms already identified by a team of plant breeders and pathologists in the disease endemic areas of the four southern districts of Kerala state, viz., Kottayam, Alappuzha, Kollam and Pathanamthitta. The criteria followed for the selection of the field resistant/tolerant mother palms are: (i) the palms should yield 80 or more nuts per year; (ii) they should be regular bearers and be absolutely free from diseases and pests; (iii) the palms should be more than 45 years old and be surrounded by palms of which at least $80 \%$ are affected by the root (wilt) disease in an endemic area; (iv) they should have typical WCT characters and (v) the palms should be negative in their reaction to the root (wilt) antiserum and the serological tests are to be repeated every year (Nair et al., 1996).

\section{DNA extraction and quantification}

Total genomic DNA was extracted from the spindle leaves of the palms using protocol developed at CPCRI (Upadhyay et al., 1999). Following ethanol precipitation, DNA was vacuum dried, resuspended in sterile TE buffer and stored at $-20^{\circ} \mathrm{C}$. The concentration of DNA samples was determined by spectrophotometric measurement at $260 \mathrm{~nm}$ and by comparison with known amounts of DNA ladder (M/s Bangalore Genei, India) on a $0.8 \%$ agarose gel stained with ethidium bromide. For PCR amplification DNA concentration was adjusted to the desired concentration by diluting with sterile water.

\section{Amplification conditions} follows:

The different PCR parameters tested are as

- Template DNA: 10, 20, $30 \mathrm{ng}$

- Taq polymerase (M/s Bangalore Genei, India): 1,2,3,4 Units

- $\quad$ Magnesium chloride: 1.5, 4, 6.5, $9 \mathrm{mM}$

- Primer concentration (M/s GIBCOBRL Life Technologies, India): 1, 5, 10, 15, 20, 25, $50 \mu \mathrm{M}$

- $\quad$ Annealing temperature: $45^{\circ} \mathrm{C}, 50^{\circ} \mathrm{C}, 55^{\circ} \mathrm{C}$

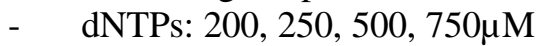

DNA amplification was performed in a $10 \mu 1$ volume. To determine the effect of a single parameter, the given parameter was varied, keeping the rest constant. A negative control (blank) containing all components of typical PCR reaction except the template DNA was used in every experiment. The PCR amplification of DNA was performed on Eppendorf Gradient Master Cycler programmed for 3 minutes initial denaturation at $94^{\circ} \mathrm{C}$ followed by 5 seconds of denaturation at $94^{\circ} \mathrm{C}, 20$ seconds annealing at $45^{\circ} \mathrm{C} / 50^{\circ} \mathrm{C} / 55^{\circ} \mathrm{C}, 30$ seconds of primer extension at $72^{\circ} \mathrm{C}$, and 5 minutes final extension at $72^{\circ} \mathrm{C}$ for a total of 35 cycles. The PCR products were stored at $-2^{\circ} \mathrm{C}$ until electrophoresis. All the experiments were repeated thrice to confirm reproducibility of the results. 


\section{Primer screening}

Sixteen arbitrary sequence decamers from the University of British Columbia (UBC) were screened for DAF analysis of coconut for detecting polymorphism between root (wilt) field resistant and susceptible palms. The details of the primers are given in Table 1.

\section{Visualization of amplification products}

Amplification products were separated by electrophoresis in $0.5 \mathrm{~mm}$ thick $5 \%$ denaturing polyacrylamide gel containing $8 \mathrm{M}$ urea. The gel was pre-run for 10 minutes and the wells were loaded with $6 \mu$ l of a 1:2 dilution of each amplification reaction with loading buffer $(40 \%$ urea, 3\% Ficoll, 0.2\% xylene cyanol, $0.2 \%$ bromophenol blue in $1 \mathrm{X}$ TBE buffer). The samples were denatured at $90^{\circ} \mathrm{C}$ for 3 min and immediately placed in ice prior to loading. Electrophoresis was run at $18 \mathrm{~W}$ constant power for 55 minutes. Molecular weights of bands were approximated using a 100bp DNA ladder (M/s Bangalore Genei, India). After electrophoresis, gels were fixed and silver stained using a slightly modified protocol of Bassam and CaetanoAnollès (1993). The gels, after staining, were lifted off on a Whatman paper (No. 1) and preserved by drying at room temperature.

\section{Gel analysis}

Silver stained gels were scanned using an image scanner (M/s Amersham Pharmacia Biotech) and MAGICSCAN software (M/s UMAX Data Systems Inc.) and the acquired images were analyzed with the programme TOTALLAB, version $2.00 \quad(\mathrm{M} / \mathrm{s}$ Nonlinear Dynamics Ltd.). The number of bands was calculated for each primer.

\section{Results and discussion}

\section{Annealing temperature}

The selection of the annealing temperature is possibly the most critical component for optimizing the specificity of a PCR reaction. The annealing temperature is a function of the length and base composition of the primer as well as the ionic strength of the reaction buffer. Three annealing temperatures were tested 45,50 and $55^{\circ} \mathrm{C}$. An annealing temperature of $45^{\circ} \mathrm{C}$ gave more non-specific bands. Amplification at $55^{\circ} \mathrm{C}$ gave good scorable bands compared to $45^{\circ} \mathrm{C}$ and $50^{\circ} \mathrm{C}$ (Fig. 1).

\section{Template DNA}

All the three levels of template DNA tested, viz., 10ng, 20ng and 30ng were amplified, of which DNA concentration of 20ng gave good scorable bands (Fig. 1).

\section{Primer concentration}

Optimal primer sequences and appropriate primer concentrations are essential for maximal specificity and efficiency in PCR. Of the seven levels of primer concentrations tested, viz., 1,5,10, 15, 20, 25 and $50 \mu \mathrm{M}$, all the levels gave amplification Primer concentration of $1 \mu \mathrm{M}$ gave very less amplification products compared to 10 $\mu \mathrm{M}$ and $15 \mu \mathrm{M}$, but $15 \mu \mathrm{m}$ gave optimum amplification products. Primer concentrations of $20,25, \quad 50 \mu \mathrm{M}$ gave higher number of amplification products (Fig. 2). Higher primer concentration may promote mis-priming and accumulation of non-specific products and increase the probability of generating primerdimer artifacts (Innis and Gelfand, 1990).

\section{Concentration of Taq polymerase}

The amount of Taq polymerase, which gave optimum amplification products was 2 Units per reaction (Fig. 3). When the Taq polymerase concentration was reduced, insufficient amounts of desired products were produced. Non-specific products were formed and the resolutions of the bands were decreased at higher enzyme levels.

\section{Concentration of $\mathrm{MgCl}_{2}$}

Lower $\mathrm{MgCl}_{2}$ concentration (1.5mM) yielded more number of amplification products while higher $\mathrm{MgCl}_{2}$ concentrations $(9.0 \mathrm{mM}$ ) 
failed to yield visible bands. The optimum $\mathrm{MgCl}_{2}$ concentration in the reaction mix was 4.0mM (Fig. 4). The $\mathrm{MgCl}_{2}$ concentration may affect one or all of the following: primer annealing, strand association temperature of both template and PCR product, product specific formation of primer-dimer artifacts and enzyme activity and fidelity (Innis and Gelfand, 1990).

\section{Concentration of dNTPs}

Of the four levels of dNTPs concentration tested, $200 \mu \mathrm{M}$ gave good and scorable bands (Fig. 5).

\section{Primer screening}

Sixteen primers were initially screened for amplification of coconut DNA (Fig. 6). Those primers, which gave optimum amplification, were then used for detecting variations between field resistant and susceptible palms. The number of scorable bands ranged from 2-29 (Table 1). Primers UBC66, UBC84 and UBC 729 could detect variations between root (wilt) field resistant and susceptible palms. A putative marker for resistance around $260 \mathrm{bp}$ was detected using UBC 84 (Fig. 7) and around 254 bp using UBC 729 (Fig. 8). UBC 66 could detect a potential marker for resistance at around $460 \mathrm{bp}$ (Fig. 9).

Presently, the cultivation of coconut palms in southern Kerala region is dependent on planting material that is resistant / tolerant to root (wilt) disease. None of the coconut accessions or hybrids tested so far at CPCRI have exhibited complete resistance to the disease. Little is known about the action and inheritance of genes for resistance to root (wilt) disease of coconut. The preponderance of susceptible palms when compared to disease-free palms in the natural population and almost half of the palms in the segregating population taking up the disease in the juvenile stage itself suggests the possibility of the disease being governed by recessive genes (Nair et al., 2003). Cardena et al. (2003) have reported identification of RAPD markers associated with resistance to lethal yellowing disease of coconut palm in resistant Malayan Yellow Dwarf and Atlantic Tall populations. The identification of West Coast Tall and Chowghat Green Dwarf field resistant palms in the disease endemic areas of southern Kerala offers hope for marker-assisted selection (MAS) strategies for resistance to root (wilt) disease in coconut. This is the first study involving identification of molecular markers linked to root (wilt) resistance / tolerance and constitutes the basis for future efforts to tag the root (wilt) resistant gene(s) in coconut. The primers identified in the present study could be valuable for identification of resistant palms from among segregating populations at the seedling stage itself.

\section{Acknowledgement}

The authors thank Dr V. Rajagopal, Director, CPCRI for his guidance and suggestions and National Agricultural Technology Programme (NATP) for financial assistance.

\section{Literature}

Anonymous, 1985. Coconut root (wilt) disease. Intensity, production loss and future strategy - a survey report. CPCRI, Kasaragod 45pp.

Anonymous. 1986. Annual Report for 1986. CPCRI, Kasaragod, India 205pp.

Assefa, S., Taliferro, C.M., Anderson, M.P., de los Reyes, B.G., and Edwards, R.M. 1999. Diversity among Cynodon accessions and taxa based on DNA amplification fingerprinting. Genome 42: 465-474.

Bassam, B.J. and Caetano-Anollés, G. 1993. Silver staining of DNA in polyacrylamide gels. Appl. Biochem. Biotechnol. 42: 181188.

Butler, E. J. 1908. Report on coconut palm disease in Travancore. Agri. Res. Inst. Pusa Bulletin No. 9, 23pp. 
Table 1. Details of UBC primers used in present study, their sequences and the number of scorable bands

\begin{tabular}{|l|l|c|c|}
\hline Primer & Sequence 5'-3' & GC/AT & $\begin{array}{c}\text { Number of scorable } \\
\text { bands }\end{array}$ \\
\hline UBC2 & CCTGGGCTTA & $6: 4$ & 21 \\
\hline UBC8 & CCTGGGGGTA & $7: 3$ & 4 \\
\hline UBC52 & TTCCCGGAGC & $7: 3$ & 20 \\
\hline UBC66 & GAGGGCGTGA & $7: 3$ & 17 \\
\hline UBC72 & CAGCACGGGA & $7: 3$ & 21 \\
\hline UBC83 & GGGCTCGTGG & $8: 2$ & 24 \\
\hline UBC84 & GGGCGCGAGT & $8: 2$ & 29 \\
\hline UBC87 & GGGGGGAAGC & $8: 2$ & 18 \\
\hline UBC88 & CGGGGGATGG & $8: 2$ & 19 \\
\hline UBC100 & ATCGGGTCCG & $7: 3$ & 2 \\
\hline UBC321 & ATCTAGGGAC & $5: 5$ & 12 \\
\hline UBC351 & CTCCCGGTGG & $8: 2$ & 20 \\
\hline UBC356 & GCGGCCCTCT & $8: 2$ & 8 \\
\hline UBC701 & CCCACAACCC & $7: 3$ & 26 \\
\hline UBC729 & CCCAACCCAC & $7: 3$ & 2 \\
\hline UBC800 & TCTCCCTCCT & $6: 4$ & \\
\hline
\end{tabular}

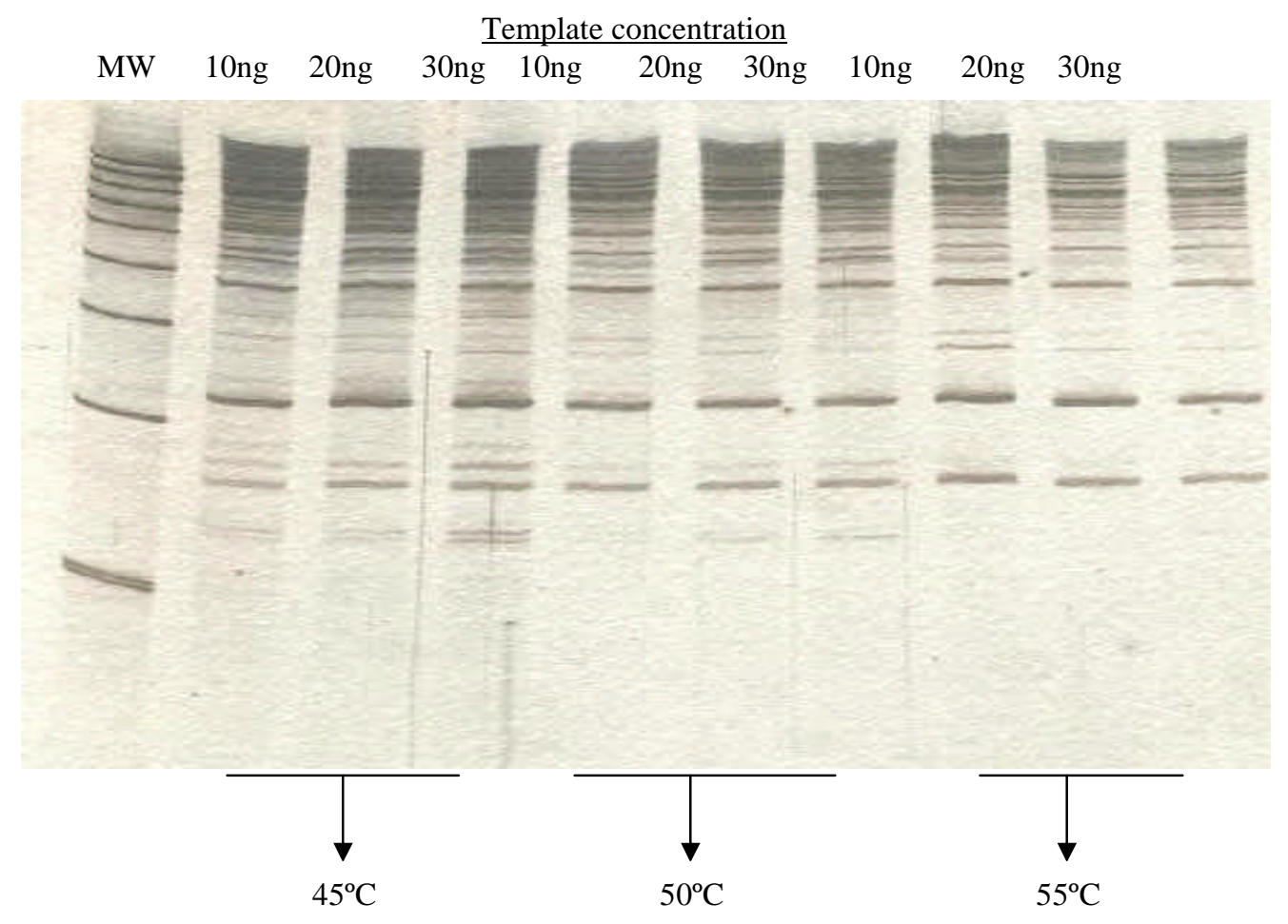

(MW: 100 bp molecular weight ladder)

Fig. 1. DAF analysis in coconut with different annealing temperatures and template concentrations 


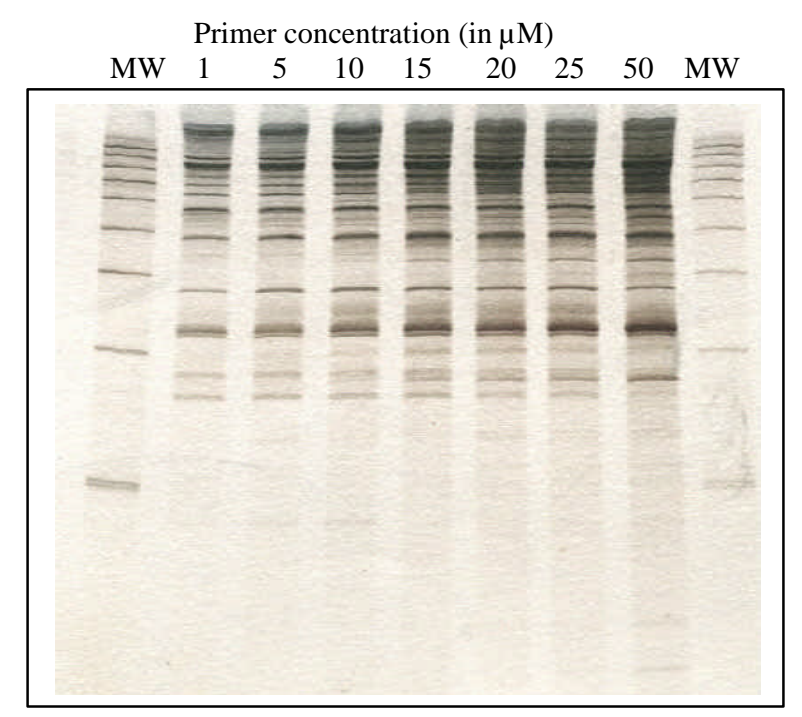

(MW: 100 bp molecular weight ladder)

Fig. 2. DAF analysis in coconut with different primer concentrations

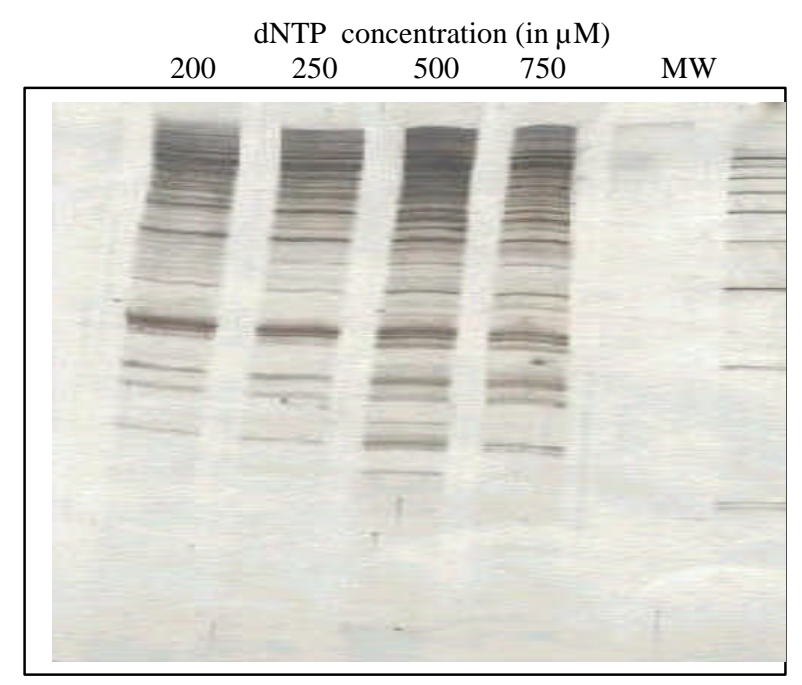

(MW: 100 bp molecular weight ladder)

Fig. 4 DAF analysis with different dNTP concentrations

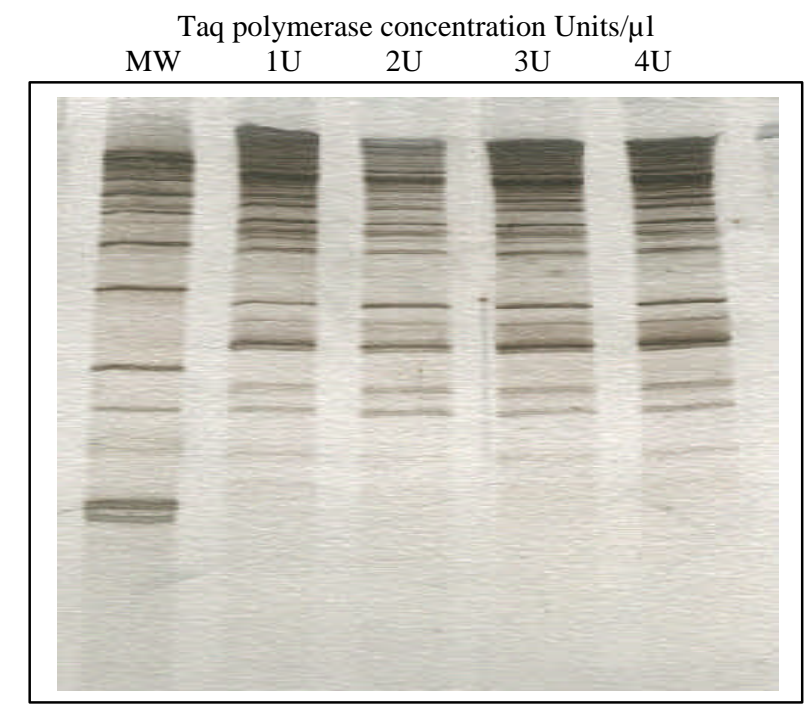

(MW: 100 bp molecular weight ladder)

Fig. 3. DAF analysis in coconut with different Taq Polymerase concentrations

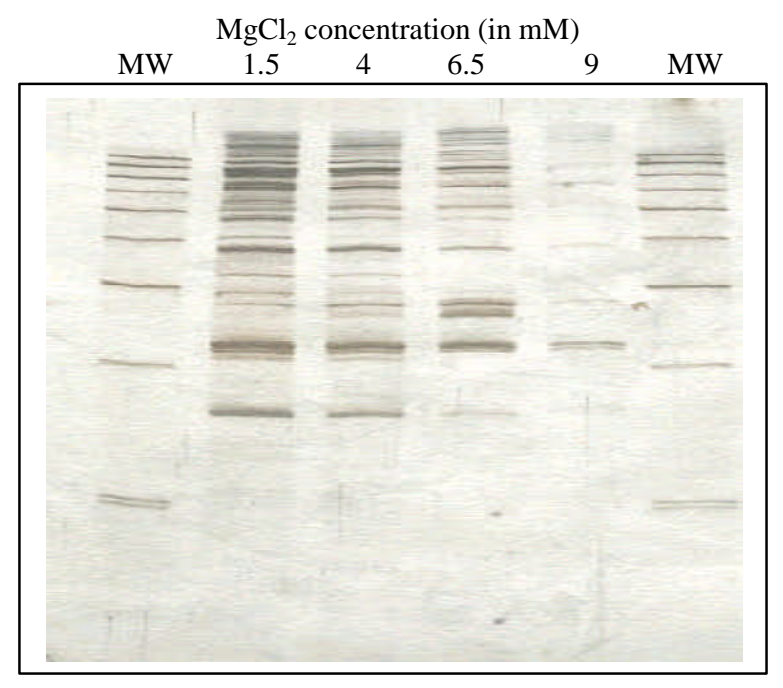

(MW: 100 bp molecular weight ladder)

Fig. 5. DAF analysis with different $\mathrm{MgCl}_{2}$ concentrations 


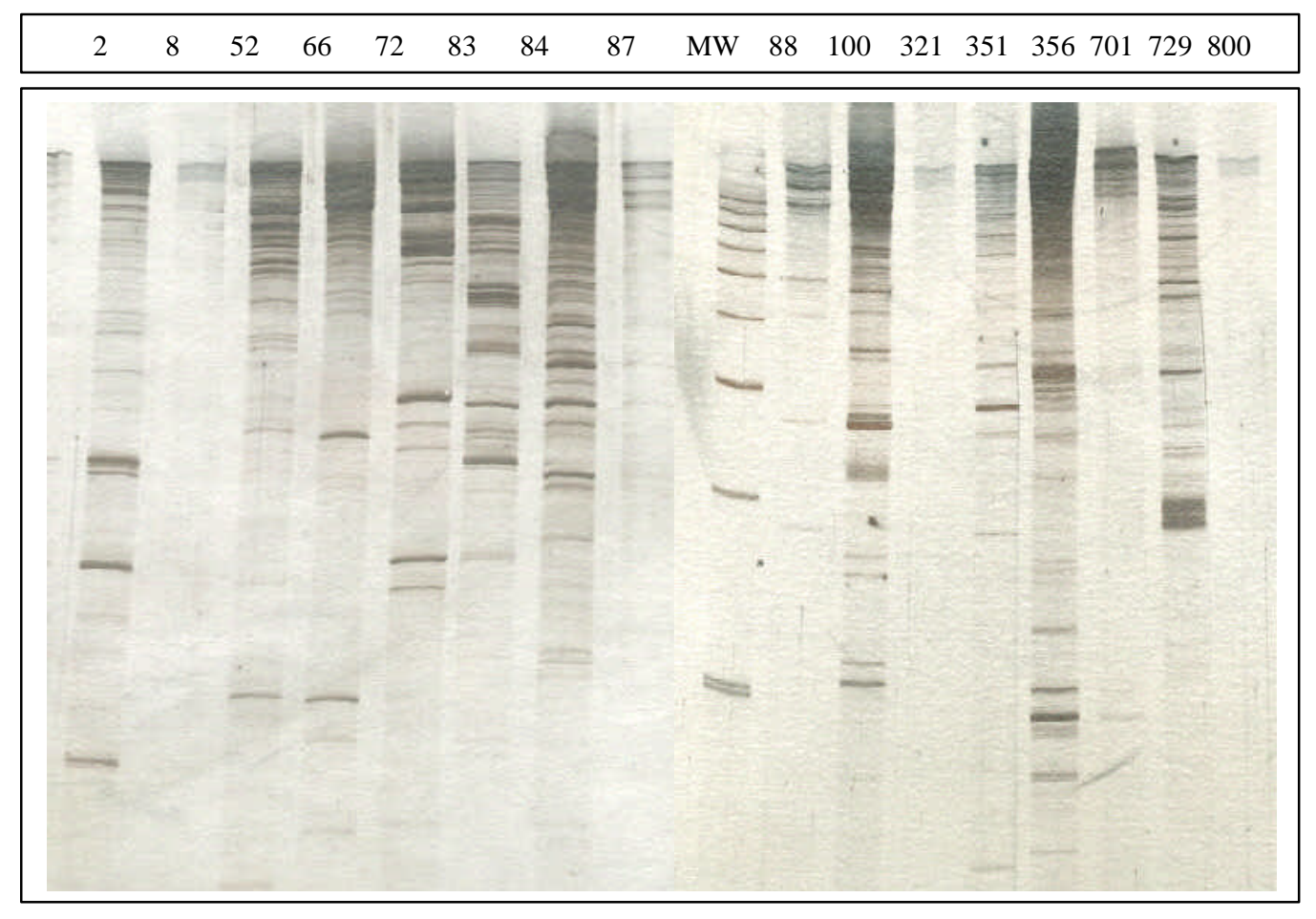

(MW: 100 bp molecular weight ladder)

Fig. 6. Screening of UBC primers for DAF analysis in coconut

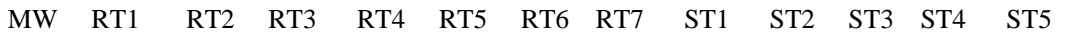

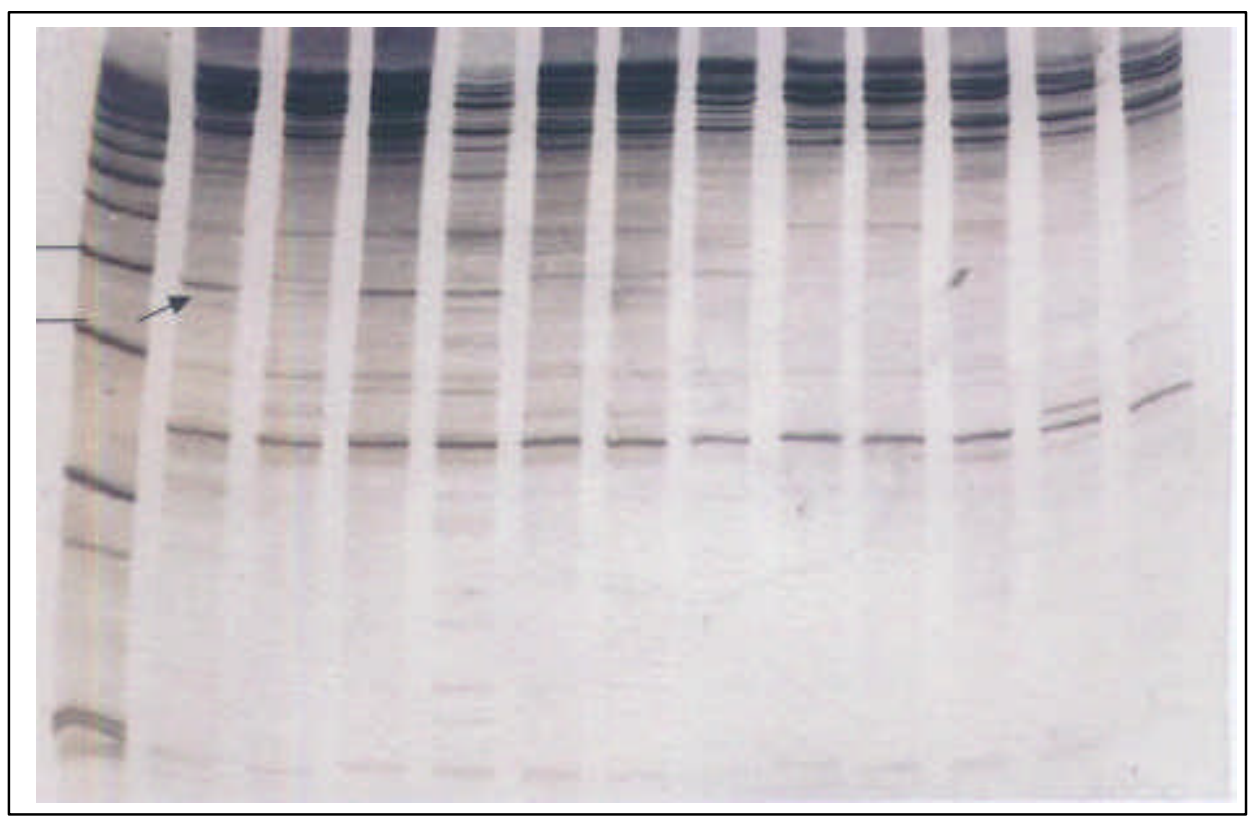

(MW - 100bp molecular marker; RT1 to RT7 Resistant Talls; ST1to ST5 - Susceptible Talls; Arrowhead indicates putative marker for resistance around $460 \mathrm{bp}$ ) 


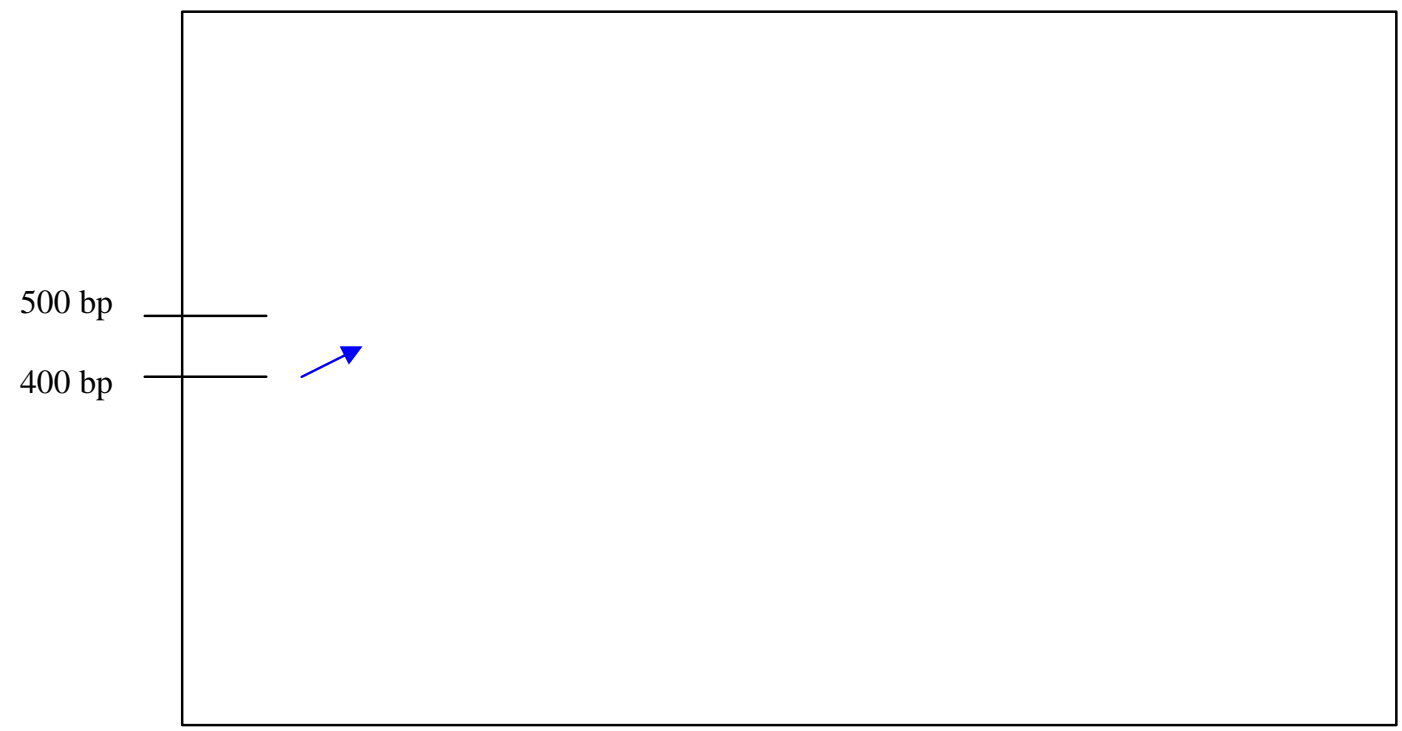

MW RT1 RT2 RT3 RT4 RT5 RT6 RT7 ST1 ST2 ST3 ST4 ST5

Ie

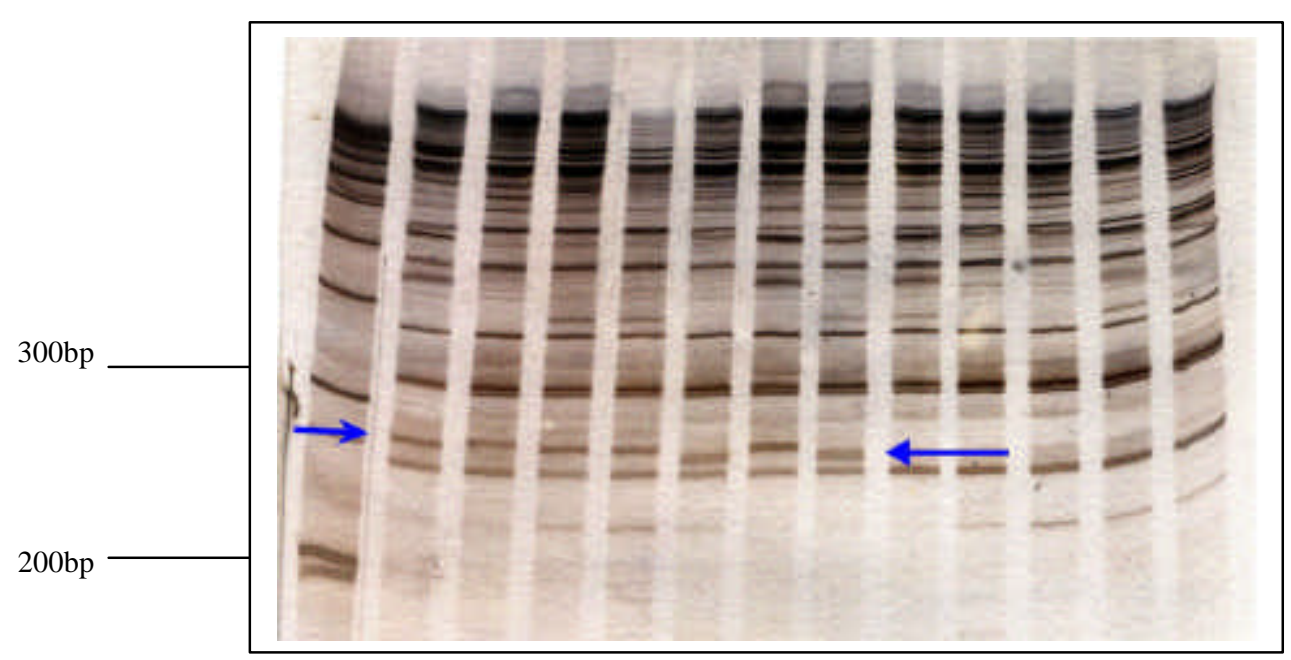

DAF analysis of UBC 66 primer: MW - 100bp Molecular marker DAF analysis of UBC 66 primer: MW - 100bp Molecular marker RT1 to RT7 Resistant Tall, ST1to ST5 - Susceptible Tall RT1 to RT7 Resistant Tall, ST1 to ST5 - Susceptible Tall

(MW - 100bp Molecular marker; RT1 to RT7 Resistant Talls; ST1 to ST5 - Susceptible

Talls; Arrowhead indicates putative marker for resistance around 260bp)

Fig. 8. DAF analysis of root (wilt) field resistant and susceptible palms using the primer UBC 84 


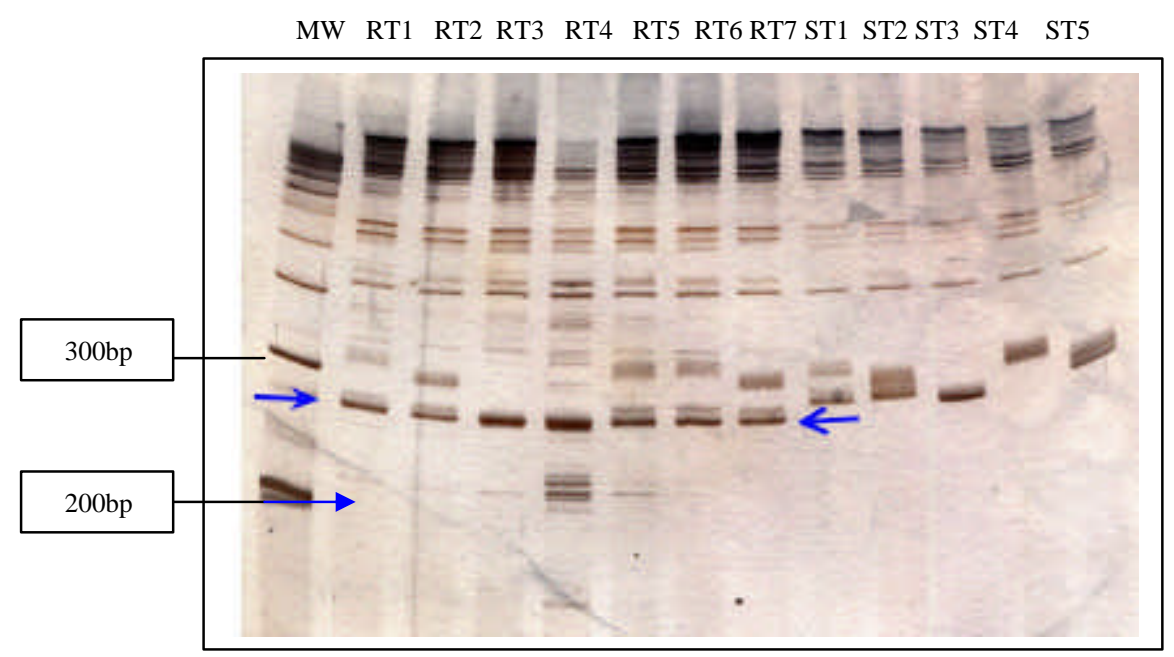

(MW: 100 bp molecular weight ladder; RT 1 to RT7: resistant mother palms; ST1 to ST5: susceptible palms; Arrowhead indicates putative marker for resistance around $254 \mathrm{bp}$ )

Fig. 9. DAF analysis of root (wilt) field resistant and susceptible palms using the primer UBC 729 
Caetano-Anollès, G., Bassam, B.J. and Gresshoff, P.M. 1991. DNA amplification fingerprinting with short arbitrary oligonucleotide primers. Biotechnol. 9: 553-557.

Caetano-Anollès, G., Bassam, B.J. and Gresshoff, P.M.1992. Primer-template interaction during DNA amplification fingerprinting with single arbitrary oligonucleotides. Molec. Gen. Genet. 235: 157-165.

Caetano-Anollès, G., Callahan, L.M., William, A.E., Weaver, K.R. and Gresshoff, P.M. 1995. DNA amplification fingerprinting analysis of Bermuda grass (Cynodon): Genetic relationships between species and interspecific crosses. Theor. Appl. Genet. 91: 228-235.

Cardena, R., Ashburner, G.R. and Oropeza, C. 2003. Identification of RAPDs associated with resistance to lethal yellowing of the coconut (Cocos nucifera L.) palm. Hort. Sci. 98: 257-263.

He, G., Prakash, C.S. and Jarret, R.L. 1995. Analysis of genetic diversity in sweet potato (Ipomoaea batatus) germplasm collection using DNA amplification fingerprinting. Genome 38: 938-945.

Innis, M.A. and Gelfand, D. H. 1990. PCR protocols: A guide to methods and application. Academic Press, New York.

Jacob, P.M., Nair, R.V. and Rawther, T.S.S. 1998. In: Coconut Root (Wilt) Disease. K.U.K. Nampoothiri and P.K. Koshy (Eds.). Codeword Process and Printers, Mangalore, India pp. 97-104.

Mathewkutty, T.I. 1998. Strategies to combat root (wilt) disease in Kerala. Indian Cocon. J. 29(4): 95-98.
Muralidharan, A., Nair, M.G. and Jayasankar, N.P. 1986. Response of coconut root (wilt) disease to management practices. Indian Cocon. J. 17(1): 3-6.

Nair, M.K., Koshy, P.K., Jacob, P.M., Nair, R.V., Bhaskara Rao, E.V.V., Nampoothiri, K.U.K. and Iyer, R.D. 1996. A root (wilt) disease resistant coconut hybrid and strategy for resistance breeding. Indian Cocon. J. 27(1): 2-5.

Nair, R.V. Jacob, P.M. Rajesh, M.G. and Thomas, R.J. 2003. Incidence of root (wilt) disease in various cross combinations of West Coast Tall variety of coconut. Cord 21 (1): 45-50.

Pillai, N.K. 1911. Naleekeram. Vidyabhivardini Press, Quilon, India.

Radha, K. and Lal, S.B. 1972. Diagnostic symptoms of root (wilt) disease of coconut. Indian J. Agric. Sci. 42: 410-413.

Richard-Molard, C., Wuilleme, S., Scheel, C., Gresshoff, P.M., Morot-Gaudry, J.F. and Limami, A.M. 1999. Nitrogen-induced changes in morphological development and bacterial susceptibility of Belgian endive (Cichorium intybus L.) are genotypedependent. Planta (Berl.) 209(4): 389-398.

Shahnejat, A.A.B., Yazdi-Samadi, B. and AbdMishani, C. 1999. Identification of DAF marker for the yellow rust resistance gene Yr5 in wheat. Iranian J. Agric. Sci. 30: 783-789.

Sreenivasan, N. 1991. Occurrence of coconut leaf rot in relation to root (wilt) disease. Indian Cocon. J. 21(10): 14-18.

Upadhyay, A., Parthasarathy, V.A., Seema, G. and Karun, A. 1999. An efficient method of DNA extraction from coconut. Agrotropica 11(1): 35-38. 
Vincent, J., Gurling, H. and Melmer, G. 1994. Oligonucleotides as short as 7-mers can be used for PCR amplification. DNA and Cell Biol. 13: 75-82.

Yazdi-Samadi, B., Young, L., Gresshoff, P.M. and Allen, F. L. 1996. Application of DAF technology to find potential markers associated with resistance to soybean cyst nematode, race 3. Soybean Genet. Newslett. 23: 230-233. 